\title{
Musculoskeletal Disability Examination by the Health Committee in Patients with Disabilities
}

\author{
(1) Yücel Bilgin¹, (1) Alican Barış², (1) Fevzi Birișik ${ }^{3}$ \\ ${ }^{1}$ Bursa Uludağ University Faculty of Medicine, Department of Orthopedics and Traumatology, Bursa, Turkey \\ 2University of Health Sciences Turkey, Haydarpașa Numune Training and Research Hospital, Clinic of Orthopedics and Traumatology, İstanbul, Turkey \\ ${ }^{3}$ University of Health Sciences Turkey, İstanbul Training and Research Hospital, Clinic of Orthopedics and Traumatology, İstanbul Turkey
}

\begin{abstract}
Introduction: This study aimed to retrospectively analyze the extent of disability, age, gender, and diagnoses to determine the areas of social support for patients who applied to the disability health board of our hospital and were found to have a musculoskeletal disability.

Methods: This study retrospectively analyzed the data of 410 patients who were evaluated in the orthopedics and traumatology outpatient clinic of our hospital's adult disability health board between 01.02.2019 and 08.06.2021. The age, gender, diagnosis, affected anatomic region, and disability rate information of patients was recorded. The musculoskeletal disability rate of all patients was determined using the "Regulation on Disability Assessment for Adults."

Results: No significant difference was found between both genders in terms of total musculoskeletal system disability rate $(p=0.17)$. The musculoskeletal system disability of the senior group was significantly higher than that of the adult group $(p<0.001)$. The most frequently affected anatomical region is the lower extremity (232 patients, 56.59\%). The most common diagnosis that leads to musculoskeletal disability includes neurological disease sequelae (23.62\% of 103 patients).

Conclusion: Our study revealed that musculoskeletal disabilities especially affect the lower extremities and the elderly patient group. Additionally, lower extremity disabilities affect the mobility of patients and create the need for social support thus should be taken into account in social planning.
\end{abstract}

Keywords: Musculoskeletal system, disability, health, sequele

\section{Introduction}

Disability is a human trait that includes medical, functional, and social aspects (1). The World Health Organization developed the International Classification of Functioning, Disability, and Health in 2001 to provide a reference framework for defining disability from a holistic biopsychosocial perspective. The purpose of classification is to form the basis to determine the policies on issues, such as health-related insurance, education, social security, economy, and fair health services delivery $(2,3)$. One of the most important issues concerning these policies is social support. Social support is defined as an asymmetric exchange of resources that is perceived as beneficial by the recipient between at least two people, the recipient and the support provider(s). Individuals with visible physical disabilities were observed to exhibit more adaptive behaviors in receiving social support than individuals without physical disabilities (4). However, disability can significantly affect an individual's access to social support, including health care. People in groups of multiple disabilities accompanied by physical disability were observed to have more problems in getting protective services and accessing health services than people with other types of disability (1). Musculoskeletal diseases are very common; however, the physical disability incidence is reported to be limited (5).

This study aimed to retrospectively analyze the amount of disability, age, gender, and diagnoses to determine the needed areas of social support in patients who applied to the disability health board of our hospital for social support and were found to have a musculoskeletal disability.

\section{Methods}

\section{Patient Selection and Data Collection}

The study retrospectively analyzed the data of 410 patients with a musculoskeletal disability who agreed to participate in the study who were evaluated in the orthopedics and traumatology outpatient clinic of our hospital's adult disability health board between 01.02.2019 and 08.06.2021. All patients were 18 years or older. The age, gender, diagnosis, affected anatomic region, and disability rate information of patients was recorded. All data were collected using the hospital registry system 
(Probel $^{\circledR}$, Turkey). The musculoskeletal disability rate of all patients was determined using the "Regulation on Disability Assessment for Adults."

\section{Ethical Approval and Informed Consent}

Our study approval was obtained from the "University of Health Sciences Turkey, İstanbul Training and Research Hospital Clinical Research Local Ethics Committee" (approval number: 2854, date: 04.06.2021). An informed consent form was obtained from all patients or their legal representatives.

\section{Statistical Analysis}

From descriptive statistical data, number, percentage, average, median, and standard deviation values were used. The normal distribution was evaluated using the Kolmogorov-Smirnov test. The data did not fit the normal distribution, thus the Mann-Whitney $\mathrm{U}$ test was used for pairwise comparisons, and the Kruskal-Wallis analysis for multiple comparisons. P-values of $<0.05$ were considered statistically significant. Statistical analysis was performed using International Business Machines Statistical Package for the Social Sciences Statistics for Windows Version 23.0 (IBM Corp. Released 2015. Armonk, NY: IBM Corp.).

\section{Results}

This study retrospectively analyzed the data of 410 patients, of whom 238 were males and 172 were females. The mean musculoskeletal system disability rate of all patients was 25.98\% (minimum-maximum: 1-98\%, median: 18\%). The mean musculoskeletal system disability rate of male patients was $25.03 \%$ (minimum-maximum : 1-98\%, median: 18\%) and that of females was $27.29 \%$ (minimum-maximum: 2-98\%, median: 19.5). No significant difference was found between both genders in terms of total musculoskeletal system disability rate $(p=0.17)$.

The mean age of patients was 53.12 years (minimum-maximum: 18-95, median: 50). Patients were divided into 3 groups according to their age: 18-24 age group was defined as "young," 25-64 age group as "adult," and 65 and over age group as "senior." The young group consisted of 19 patients, the adult group with 286 patients, and the senior group with 105 patients. The mean musculoskeletal system disability rate was $31.79 \%$ (minimum-maximum: 4-98\%, median: 22\%), 21.09\% (minimum-maximum: 1-98\%, median: $8 \%$ ), and 38.23\% (minimummaximum: 4-98\%, median: 24\%) in the young, adult, and senior groups, respectively. The statistical analysis using the Kruskal-Wallis analysis revealed a significant difference between the 3 groups $(p<0.001)$. The musculoskeletal system disability of the senior group was significantly higher than the adult group $(p<0.001)$ (Table 1, 2).

The anatomical regions of patients that cause musculoskeletal disability were divided into 3 regions as upper extremity, lower extremity, and spine. The most frequently affected anatomical region is the lower extremity (232 patients, 56.59\%) followed by the upper extremity (152 patients, 37.07\%) and spine (117 patients, 28.54\%).

The evaluation of patients in terms of disease diagnosis that caused musculoskeletal disability revealed that 410 patients were diagnosed with 436 diseases. The most common diagnosis that leads to musculoskeletal disability was neurological disease sequelae (23.62\% of 103 patients) followed by traumatic injuries (21.33\% of 93 patients). The detailed distribution according to the diagnoses is shown in Table 3. The evaluation of diagnoses according to age groups revealed that the most common diagnoses in the young group are traumatic injuries (33.3\%) and neurological disease sequelae (33.3\%), whereas traumatic injuries (24.10\%) in the adult group and degenerative disease sequelae (44.14\%) in the senior group.

\section{Discussion}

With an increased care condition, the demand for health services increases in parallel with the increased number of the disabled population and increased life expectancy. Disabilities affect people, especially in medical, psychological, and physical aspects (6). Physiological effects are especially the result of pathologies that concern the musculoskeletal system. A few original research has been conducted to describe the musculoskeletal disability in the Turkish population. However, knowing the content of disabilities will pave the way for the development of physical and social support projects that will be necessary for many steps, from prevention to rehabilitation.

Musculoskeletal disability is one of the most common causes of disability (7). Koçak et al. (8) revealed that the most common causes of disability were cardiovascular, musculoskeletal, and visual system pathologies. Our study revealed that the most common causes of musculoskeletal disability are neurological disease sequelae, traumatic injuries, and degenerative diseases. A Kocaeli-based study from our country revealed that the most common pathologies include degenerative diseases and neurological disease sequelae (9).

Aging also increases degenerative diseases. Arslan and Kutsal (10) revealed osteoarthritis as the second most common cause of disability in geriatric patients. Our study revealed a significantly higher disability rate of the senior group than the adult group. The most common diagnoses include degenerative disease sequelae in the senior group, which supports our current opinion.

Musculoskeletal disabilities are thought to physically affect people; however, they can affect many systems of the body. Psychologically, Razuvaeva et al. (11) revealed that people with musculoskeletal

\begin{tabular}{|c|c|c|c|}
\hline Musculoskeletal system disability & $\begin{array}{l}\text { Young } \\
\text { group }\end{array}$ & $\begin{array}{l}\text { Adult } \\
\text { group }\end{array}$ & $\begin{array}{l}\text { Senior } \\
\text { group }\end{array}$ \\
\hline Rate (\%) & 31.79 & 21.09 & 38.23 \\
\hline Standard deviation $( \pm)$ & 28.36 & 17.34 & 14.02 \\
\hline Median (\%) & 22 & 8 & 24 \\
\hline Minimum-maximum (\%-\%) & $4-98$ & $1-98$ & $4-98$ \\
\hline$p$-value* & - & $p<0.001$ & - \\
\hline
\end{tabular}

Table 2. Comparison of disability rates by age groups (*according to the Mann-Whitney $U$ analysis)

\begin{tabular}{|l|l|l|l|}
\hline & $\begin{array}{l}\text { Young group-adult } \\
\text { group }\end{array}$ & $\begin{array}{l}\text { Young group- } \\
\text { senior group }\end{array}$ & $\begin{array}{l}\text { Adult group- } \\
\text { senior group }\end{array}$ \\
\hline p-value* & 0.095 & 0.162 & $p<0.001$ \\
\hline
\end{tabular}


Table 3. Distribution of musculoskeletal disabilities by age groups and diagnoses

\begin{tabular}{|c|c|c|c|c|c|c|c|c|}
\hline \multirow[b]{2}{*}{ Diagnosis } & \multicolumn{2}{|c|}{ Young group } & \multicolumn{2}{|c|}{ Adult group } & \multicolumn{2}{|c|}{ Senior group } & \multicolumn{2}{|c|}{ Total } \\
\hline & $\mathbf{n}$ & $\%$ & $\mathbf{n}$ & $\%$ & $\mathbf{n}$ & $\%$ & $\mathbf{n}$ & $\%$ \\
\hline Cervical discopathy & 0 & 0.00 & 28 & 9.12 & 3 & 2.70 & 31 & 7.11 \\
\hline Traumatic injury & 6 & 33.33 & 74 & 24.10 & 13 & 11.71 & 93 & 21.33 \\
\hline Lumbar discopathy & 0 & 0.00 & 56 & 18.24 & 7 & 6.31 & 63 & 14.45 \\
\hline Degenerative disease & 0 & 0.00 & 39 & 12.70 & 49 & 44.14 & 88 & 20.18 \\
\hline Congenital disease & 4 & 22.22 & 18 & 5.86 & 1 & 0.90 & 23 & 5.28 \\
\hline Acquired deformity & 1 & 5.56 & 8 & 2.61 & 1 & 0.90 & 10 & 2.29 \\
\hline Neurologic disease & 6 & 33.33 & 65 & 21.17 & 32 & 28.83 & 103 & 23.62 \\
\hline Rheumatologic disease & 0 & 0.00 & 6 & 1.95 & 0 & 0.00 & 6 & 1.38 \\
\hline Vascular disease & 0 & 0.00 & 7 & 2.28 & 5 & 4.50 & 12 & 2.75 \\
\hline Chronic infection & 0 & 0.00 & 1 & 0.33 & 0 & 0.00 & 1 & 0.23 \\
\hline Tumor & 1 & 5.56 & 5 & 1.63 & 0 & 0.00 & 6 & 1.38 \\
\hline Total & 18 & 100 & 307 & 100 & 111 & 100 & 436 & 100 \\
\hline
\end{tabular}

disabilities have the low adaptive capacity, high neuropsychic stress, low self-regulation, and no ability to plan conscious activities. Additionally, it can cause secondary comorbidities, such as obesity, hypertension, and pressure sores (12). Therefore, the need for medical support and rehabilitation of people with disabilities is high. According to the study of Yöndemli (13), the need for rehabilitation in people with disabilities is $29.8 \%$.

As in our study, such descriptive studies will guide the necessary projects for the problems of patients with musculoskeletal disabilities. One of the important problems of people with musculoskeletal disabilities is the obstacles they encounter in doing active sports. In 2010, Gegenwarth and Reinelt (14) developed suitable equipment for people with a musculoskeletal disability as defined in their society to do winter sports.

Disability diagnosis is made with the health reports prepared by the disability health boards in our country. However, the increased number of disabled patients over the years increased the amount of work in health boards. Therefore, people with disabilities experience problems. Additionally, recent studies focused on computer-aided diagnosis methods. Öztuna and Elhan (15) used a computer-assisted method to determine the disability in low back pain and osteoarthritis pathologies and detected a high degree of compatibility. Thus, a transition to these methods may occur in the future.

\section{Study Limitations}

Our study limitations include its retrospective design, single-center, and registry data basis. The inclusion of many health institutions from many regions in such descriptive studies will provide a more objective distribution.

\section{Conclusion}

Our study revealed that musculoskeletal disabilities especially affect the lower extremities. Elderly patients have a higher disability rate than adult patients. No difference was found between genders in terms of disability rate. The most common causes in etiology include neurologic disease sequelae, traumatic injuries, and degenerative diseases. Lower extremity disabilities also affect patients' mobility and lead to necessary social support. Therefore, these data should be considered in planning for future projects for the disabled.

Ethics Committee Approval: Our study approval was obtained from the "University of Health Sciences Turkey, İstanbul Training and Research Hospital Clinical Research Local Ethics Committee" (approval number: 2854, date: 04.06.2021).

Informed Consent: An informed consent form was obtained from all patients or their legal representatives.

Peer-review: Externally peer-reviewed.

Authorship Contributions: Concept - F.B.; Design - Y.B.; Data Collection or Processing - Y.B., A.B., F.B.; Analysis or Interpretation - Y.B., A.B.; Literature Search - F.B.; Writing - Y.B., A.B., F.B.

Conflict of Interest: No conflict of interest was declared by the authors.

Financial Disclosure: The authors declared that this study received no financial support.

\section{References}

1. McClintock HF, Kurichi JE, Kwong PL, Xie D, Streim JE, PEzzin LE, et al. Disability stages and trouble getting needed health care among medicare beneficiaries. Am J Phys Med Rehabil 2017; 96: 408-16.

2. DIN P. International classification of functioning, disability and health. 2001. http://www.solcoct.it/seminari/din programma25-11. pdf

3. Escorpizo R. Defining the principles of musculoskeletal disability and rehabilitation. Best Pract Res Clin Rheumatol 2014; 28: 367-75.

4. Orr E, Thein RD, Aronson E. Orthopedic disability, conformity, and social support. J Psychol 1995; 129: 203-19.

5. Nota SPFT, Bot AGJ, Ring D, Kloen P. Disability and depression after orthopaedic trauma. Injury 2015; 46: 207-12. 
6. Estrella-Castillo DF, Gómez-De-Regil L. Quality of life in Mexican patients with primary neurological or musculoskeletal disabilities. Disabil Health J 2016; 9: 127-33.

7. Naçar M, Çetinkaya F, Baykan Z. Prevalence of impairments, disabilities, handicaps: a study from Kayseri province. TAF Prev Med Bull 2012; 11: 71-80.

8. Koçak FA, Kurt EE, Şaș S, Koçak Y, Erdem HR, Tuncay F, et al. Disability distribution of geriatric patients applying to the board of health for disabled in a rural region. Turk Osteoporoz 2018; 24: 92-9.

9. Terzi R, Altin F. Examination of the patient's locomotor system disability evaluated in the board of health for disabled. Turk J Osteoporosis 2014; 20: 60-4.

10. Arslan \$, Kutsal GY. A multigenter epidemiological study to evaluate the prevalance of disability in the elderly. Geriatri 1999; 2: 103-14.
11. Razuvaeva T, Gut Y, Lokteva A, Pchelkina E. The problem of psychological rehabilitation of persons with disorders of the musculoskeletal system acquired in adulthood. Behav Sci (Basel) 2019; 9: 133.

12. Rimmer JH. Health promotion for people with disabilities: The emerging paradigm shift from disability prevention to prevention of secondary conditions. Phys Ther 1999; 79: 495-502.

13. Yöndemli H. http://https://acikbilim.yok.gov.tr/handle/20.500.1281 2/453173

14. Gegenwarth T, Reinelt T. The 'adapted skibob' - wintersport for people with specials needs \& disabilities of the musculoskeletal system. Procedia Engineering 2010; 2: 3143-9.

15. Öztuna D, Elhan H. https://dspace.ankara.edu.tr/xmlui/handle/20. $500.12575 / 36875$ 